ERNEST IRLANDQ LAWRENCE

BERKELEY NATIDNAL LABםRATGRY

\title{
Two- and Three-Dimensional Natural and Mixed Convection Simulation Using Modular Zonal Models
}

E. Wurtz, J.-M. Nataf, and F. Winkelmann Energy and Environment Division

July 1996 


\section{DISCLAIMER}

This document was prepared as an account of work sponsored by the United States Government. While this document is believed to contain correct information, neither the United States Government nor any agency thereof, nor The Regents of the University of California, nor any of their employees, makes any warranty, express or implied, or assumes any legal responsibility for the accuracy, completeness, or usefulness of any information, apparatus, product, or process disclosed, or represents that its use would not infringe privately owned rights. Reference herein to any specific commercial product, process, or service by its trade name, trademark, manufacturer, or otherwise, does not necessarily constitute or imply its endorsement, recommendation, or favoring by the United States Government or any agency thereof, or The Regents of the University of Califomia. The views and opinions of authors expressed herein do not necessarily state or reflect those of the United States Govemment or any agency thereof, or The Regents of the University of Califomia.

Available to DOE and DOE Contractors from the Office of Scientific and Technical Information

P.O. Box 62, Oak Ridge, TN 37831

Prices available from (615) 576-8401

Available to the public from the National Technical Information Service

U.S. Department of Commerce

5285 Port Royal Road, Springfield, VA 22161

Emest Orlando Lawrence Berkeley National Laboratory is an equal opportunity employer. 


\section{TWO- AND THREE-DIMENSIONAL NATURAL}

\section{AND MIXED CONVECTION SIMULATION}

\section{USING MODULAR ZONAL MODELS}

by

Etienne Wurtz

Laboratoire d'Etudes Pour la Thermique Appliquee au Batiment Université de la Rochelle

Rochelle, France

\section{and}

Jean-Michel Nataf and Frederick Winkelmann

Energy and Environment Division

Lawrence Berkeley National Laboratory

University of California

Berkeley, California 94720, USA

July 1996

This work was partially supported by the Assistant Secretary for Energy Efficiency and Renewable Energy, Office of Building Technologies, Building Systems and Materials Division of the U.S. Dept. of Energy, under Contract No:DE-AC03-76SF00098. 


\section{DISCLAIMER}

Portions of this document may be illegible in electronic image products. Images are produced from the best available original document. 


\title{
Two- and Three-Dimensional Natural and Mixed Convection Simulation Using Modular Zonal Models
}

\author{
Etienne Wurtz \\ L.E.P.T.A.B. Université de La Rochelle, La Rochelle, France \\ Jean-Aichel Nataf and Frederick Winkelmann \\ Lamrence Berkeley National Laboratory, Berkeley; CA 94720, USA
}

July 1996

\begin{abstract}
We demonstrate the use of the zonal model approach, which is a simplified method for calculating natural and mixed conrection in rooms. Zonal models use a coarse grid and use balance equations. state equations, hydrostatic pressure drop equations and power law equations of the form $m=C^{\prime} \Delta^{n}$. The advantages of the zonal approach and its modular implementation are discussed. The zonal model resolution of nonlinear equation sy.stems is demonstrated for three cases: a 2-D room, a 3-D room and a pair of 3-D rooms separated by a partition with an opening. A sensitivity analysis with respect to physical parameters and grid coarseness is presented. Results are compared to computational fluid dynamics (CFD) calculations and experimental data.
\end{abstract}

\section{Introduction}

The study of air flow in buildings is important for the evaluation of energy consumption, moisture and pollutant transport, and comfort. The physical phenomenona at work are natural or forced convection.

Natural convection has been extensively studied from theoretical, numerical and experimental points of view. The theory considers laminar boundary layer similarity or nonsimilarity solutions, as for example in [Bej84]: [SYT1], [CE76] and [IJH87]. Many results have been obtained on standard problems, such as the "window problem", in which natural convective flow occurs in a room with both hot and cold surfaces ([BGKG80], [Dav82], [Dav83]. [MP83]. [MP84]). Variations in geometry have been addressed ( [SGT81], [TG82]). Real rooms. with or without forced convection, have for the most part been analyzed using CFD. as in [Gad80], [SM191]. [NidK93], and, with obstacles, in [GAC.91]. CFD has also been used for large rooms and whole buildings ([LYT93]; [BNIS91], [SS93]).

The major difficulty with CFD, especially in three dimensions, is that the calculations are very slow and require large amounts of memory. Some methods, like the multigrid method [LHF93], mitigate the problem but still require significant computational resources. Furthermore, the sheer size of the output requires considerable effort in postprocessing and risualization. 
Other methods bypass the fluid mechanics equations. An example is the one-air-node approach. which is often used for multizone air flow calculations ([FA89]. [HC.91]). The main drawback of this approach is the coarseness of the results. This method. when coupled with C:FD as is sometimes done ([SM:91], [CC:95]), suffers from the inherent difficulties of the C:FD approach.

An intermediate approach is needed that allows the flow pattern inside a room to be determined without the computational investment of C.FD. One such approach is the "zonal method."

\section{The Zonal Method}

\subsection{Previous Work}

The zonal method. which is not new. is based on heat and mass balance equations in macroscopic volumes. Added to this is a relationship between mass flow and pressure difference. The zonal method should not be confused with models used to calculate air flow between rooms ([Wal84]: [Oku8T]. [FA89]. [HC.91]. [TS93]).

Initial work on the zonal method emphasized how to partition the computational domain in two dimensions ([LN8i]. [How85]) [Ina88]). A systematic attempt to use the zonal method with power law equations on arbitrary geometries in two dimensions is described in [BD91]. in which convergence problems were encountered and the results did not agree well with measurements.

The present work treats the 3-D simulation case, with natural or mixed convection. Results were validated against CFD calculations and measurements. In addition we coupled 3-D zonal models with models for thermal comfort, wall conduction and directed flow. Other studies ([RAC93]. [RAC94]) have considered the 3-D case. but did not couple to other models and were not validated.

\subsection{Presentation of the method}

In the 3-D zonal method the room air is partitioned into 3-D zones. Adjacent zones exchange mass and energy: The following mass and energy balance equations apply to each zone:

$$
\begin{aligned}
& \sum q_{m}+q_{\text {source }}-q_{\text {sink }}=0 \\
& \sum \Phi+\Phi_{\text {source }}-\Phi_{\text {sink }}=0
\end{aligned}
$$

where $\sum q_{m}$ is the sum of mass flows across the interfaces of the zones, $q_{\text {source }}$ is the mass flow from sources in the zone, $q_{\text {sink }}$ is the mass flow to sinks in the zone, $\sum \Phi$ is the sum of heat transfers through the interfaces of the zone, $\Phi_{\text {source }}$ is the heat transfer from sources in the zone and $\Phi_{\text {sink }}$ is the heat transfer to sinks in the zone.

We assume that a zone has uniform temperature and density and that the pressure at the middle of a zone obevs the perfect gas law:

$$
P_{\text {middl }}=\rho \frac{R}{M} T
$$

where $\rho$ is the density, $R$ the perfect gas constant. $M$ the molar mass and $T$ the absolute temperature. 
The pressure at height $z$ abore the bottom of a zone is given by

$$
P=P_{0}-\rho g z
$$

where $P_{0}$ is the pressure at the bottom of the zone.

Assuming that the zones are rectangular parallelopipeds with edges oriented along the coordinate axes. the gist of the zonal model lies in the following equations:

for horizontal interfaces.

$$
q_{m_{v e r t}}=C \rho S\left(P-P_{t o p}\right)^{n}
$$

for vertical interfaces,

$$
\begin{gathered}
\Delta P=\Delta P_{0}-\Delta \rho g z \\
z_{n}=\frac{\dot{\Delta} P_{0}}{\Delta \rho g} \\
q_{m_{\text {sup }}}=C l \rho(\Delta \rho g)^{n} \frac{\left(h-z_{n}\right)^{n+1}}{n+1} \\
q_{m_{\text {inf }}}=C l \rho(\Delta \rho g)^{n} \frac{\left(z_{n}\right)^{n+1}}{n+1} \\
q_{m}=q_{m_{\text {sup }}}+q_{m_{\text {inf }}}
\end{gathered}
$$

Here $P_{\text {top }}$ is the pressure at the top of the zone. $q_{m}$ are mass flows, $C$ is an empirical constant equal to $0.83 \mathrm{mis}^{-1} \mathrm{~Pa}^{-n}$ [Ina88], $l$ is the width of a zone, $h$ is the height of a zone. $n$ is a fractional exponent, $\Delta$ is a difference operator between two horizontally adjacent zones: $z_{n}$ is the height of the neutral point (the point at which pressures on either side of the interface between two zones are equal), $p$ is the volumetric mass, vert is an index for vertical mass flow: $m_{\text {sup }}$ an index for horizontal mass flow above the neutral point and $m_{\text {inf }}$ is an index for horizontal mass flow below the neutral point. It is assumed that flow is incompressible and pressure drop is hydrostatic.

Energy fluxes are calculated using the following equations. which are valid for temperatures typically found in buildings and which, for now, neglect humidity:

$$
\begin{gathered}
\Phi_{\text {horiz }}=q_{m s} c_{p} T_{s}+q_{m e} c_{p} T_{\epsilon} \\
\Phi_{\text {vert }}=q_{m_{\text {vert }}} c_{p} T_{v \in r t}
\end{gathered}
$$

where $\Phi$ denotes a heat flux, horiz stands for horizontal and vert for vertical. Here $q_{m}$, denotes mass flow leaving the zone and $q_{m_{e}}$ denotes mass flow entering the zone. $T_{s}$ is the temperature of the air leaving the zone, which is the same as the zone temperature, and $T_{\epsilon}$ the temperature of the air entering the zone. $T_{v \epsilon r t}$ is the zone temperature for vertical flow out of the zone and is the adjacent zone temperature for vertical flow into the zone. We use a sign convention such that a mass flow is positive when the flow is in the positive direction of an $x, y$ or $z$ axis, and negative when in the negative direction of an axis. 


\subsection{Physical Considerations}

Several remarks can be made about the validity of the model. (1) Coarse grids and high temperature gradients may make uniform temperature in a zone a poor assumption. (2) Temperature and velocity boundary layers are not accounted for. (3) The hydrostatic pressure approximation is valid only for flows with parallel streamlines. (4) Only one neutral point per vertical interface between zones is allowed, which, depending on the gridding. affects the qualitative behavior of the solution. (5) Along the lines of [BD91], the Bernoulli equation used amounts to assuming that kinetic energy is fully dissipated within the bounds of a single zone, and so does not apply to plumes or jets that span two or more zones. as rediscovered in [R.AC93].

\subsection{Numerical Considerations}

An obvious property of the above equations is their nonlinearity. The $n=0.5$ exponent is a source of particular numerical difficulty since it is well known that standard Tewton-Raphson iteration (without relaxation) does not converge when there are squareroot dependencies. An additional source of trouble is that. because they depend on flow direction. the equations must be piecewise defined, even if they are formally unified, as in [HvdMR 93]. Finally: 3-D problems generally lead to a fairly large number of equations. This "dimensional curse" also exists for zonal models. For example, some problems analyzed with zonal methods require resolving more than 2000 equations.

\subsection{Insight on a Simplified Case: the Window Problem}

\subsubsection{Two-Zone Case}

We consider now the application of the zonal model to the well-known "window" problem in which a two-dimensional rectangular carity is heated by a warm isothermal wall on the left and cooled by a cold window (in our case, actually a cold isothermal wall) on the right. The ceiling and floor are assumed to be adiabatic. For this configuration the room air density will. on arerage, be smaller on the left, and the resulting circulation will be clockwise. We divide the room into tu: zones, one on the left and one on the right. Because of buovancy effects we expect the air to flow from left to right at the top of the room and from right to left at the bottom. We assume that there are no mass sources or sinks. that the convection at the walls is Newtonian and that $n=0.5$. The solution will be given in terms of the widths, $l_{1}$ and $l_{2}$. of the left and right zones, respectively: the height. $h$ of the zones, the convective heat transfer coefficients, $h_{h}$ and $h_{c}$, of the hot and cold walls. respectively: the hot and cold wall temperatures, $t_{h}$ and $t_{c}$, respectively; and the total room air mass. $m$.

\subsubsection{Algebraic Simplification in the Two-Zone Case}

Simplification by substitution produces a nonlinear system of two equations and two unknowns. The simplification was done automatically using the MACSYMA computer algebra program [MITS3]. The simplification algorithm that was used is described in [Nat92]. Basically, the algorithm transforms the equation system into a graph and then uses graph theory to find a small number of iteration variables. 
During the simplification process MACSYMA asks questions. such as whether the neutral point is located above the height of a zone or not. which zone has the higher specific air mass, $\rho$ : etc. The answers to these questions are unique, even though, in some cases. an intermediate calculation of the sign of expressions is required (such as whether $\left.h_{c}\left(t_{c}-t_{1}\right)+h_{h}\left(t_{h}-t_{1}\right)>0\right)$. The resulting simplified system of equations is also unique.

The unknowns remaining after simplification by MACSYMA are $t_{2}$ and $\rho_{2}$. the air temperature and density: respectively, of the right-hand zone. However, this simplification is not complete. due to the presence of fractional powers. which lead to alternative solutions that MACSYMA cannot resolve. Further simplification can be carried out, producing one (very nonlinear) equation in $\rho_{2}$ that can be solved numerically. Note that if fractional power simplification is turned on in MACSYMA, two equations, in $\rho_{2}$ and $z_{n}$ : result.

Results from the computer algebra reduction agree with numerical results obtained with an independent numerical solver , called SPARK, which is described in section 3 . However. the final equations are too unwieldy to use, and there are two of them, in terms of moderately interesting variables. We would be more interested in only one final equation (since resolution of one nonlinear equation, however complicated, can be done efficiently and safely). possibly in terms of one mass flow, $q_{m}$, for example (since what we are mainly interested in is the heat transfer and the mass circulation). The conclusion of interest of this model is the global heat transfer, from the left wall to the right wall.

Reordering the set of equations and reformulating the pressure power law equations to express them with the $\rho$ 's solved for. one can actually get down to one equation with residual unknown $\rho_{2}$. The (large) surviving equation given by the MACSYMA implementation of the reduction algorithm is:

$\mathrm{H} / 2=$

$(\mathrm{SQRT}(\mathrm{G}) * \mathrm{SQRT}(\mathrm{H}) * \mathrm{SQRT}(\mathrm{L} 1) * \operatorname{SQRT}((\mathrm{L} 2+\mathrm{L} 1) * \mathrm{RHO} 2+(-\mathrm{L} 2-\mathrm{L} 1) * \mathrm{RHO}) *(((2 * \operatorname{SQRT}(2) * \mathrm{C} \#$ $\mathrm{P} * \mathrm{HHOT} * \mathrm{~K} * \mathrm{~L} 2+2 * \mathrm{SQRT}(2) * \mathrm{CP} * \mathrm{HHOT} * \mathrm{~K} * \mathrm{~L} 1) * \mathrm{R} * \mathrm{RHO} * \mathrm{RHO} 2+(-2 * \mathrm{SQRT}(2) * \mathrm{CP} * \mathrm{HHOT} * \mathrm{~K} * \mathrm{~L} 2-2 * \mathrm{SQRT} \#$ (2) $* \mathrm{CP} * \mathrm{HHOT} * \mathrm{~K} * \mathrm{~L} 1) * \mathrm{R} * \mathrm{RHO} \sim 2) * \mathrm{THOT}+((2 * \mathrm{SQRT}(2) * \mathrm{CP} * \mathrm{HCOLD} * \mathrm{~K} * \mathrm{~L} 2+2 * \mathrm{SQRT}(2) * \mathrm{CP} * \mathrm{HCOLD} * \mathrm{~K} \#$ *L1) $* \mathrm{R} * \mathrm{RHO} * \mathrm{RHO} 2+(-2 * \mathrm{SQRT}(2) * \mathrm{CP} * \mathrm{HCOLD} * \mathrm{~K} * \mathrm{~L} 2-2 * \mathrm{SQRT}(2) * \mathrm{CP} * \mathrm{HCOLD} * \mathrm{~K} * \mathrm{~L} 1) * \mathrm{R} * \mathrm{RHO}-2) * \mathrm{TC} \#$ $\mathrm{OLD}+((\mathrm{SQRT}(2) * \mathrm{CP} * \mathrm{G} * \mathrm{H} * \mathrm{HHOT}+\mathrm{SQRT}(2) * \mathrm{CP} * \mathrm{G} * \mathrm{H} * \mathrm{HCOLD}) * \mathrm{~K} * \mathrm{~L} 2+(\mathrm{SQRT}(2) * \mathrm{CP} * \mathrm{G} * \mathrm{H} * \mathrm{HHOT}+\mathrm{SQRT} \#$ (2) $* \mathrm{CP} * \mathrm{G} * \mathrm{H} * \mathrm{HCOLD}) * \mathrm{~K} * \mathrm{~L} 1) * \mathrm{MAIR} * \mathrm{RHO} * \mathrm{RHO} 2+((-\mathrm{SQRT}(2) * \mathrm{CP} * \mathrm{G} * \mathrm{H} * \mathrm{HHOT}-\mathrm{SQRT}(2) * \mathrm{CP} * \mathrm{G} * \mathrm{H} * \mathrm{HC} \#$ OLD ) $* \mathrm{~K} * \mathrm{~L} 2+(-\mathrm{SQRT}(2) * \mathrm{CP} * \mathrm{G} * \mathrm{H} * \mathrm{HHOT}-\mathrm{SQRT}(2) * \mathrm{CP} * \mathrm{G} * \mathrm{H} * \mathrm{HCOLD}) * \mathrm{~K} * \mathrm{~L} 1) * \mathrm{MAIR} * \mathrm{RHO} \sim 2)+(12 * \mathrm{HC} \#$ $\mathrm{OLD} * \mathrm{HHOT} * \mathrm{~L} 1 * \mathrm{~L} 2 * \mathrm{R} * \mathrm{RHO} 2+(-12 * \mathrm{HCOLD} * \mathrm{HHOT} * \mathrm{~L} 1 * \mathrm{~L} 2-12 * \mathrm{HCOLD} * \mathrm{HHOT} * \mathrm{~L} 1-2) * \mathrm{R} * \mathrm{RHO}) * \mathrm{THOT}+12 \#$ $* \mathrm{HCOLD} * \mathrm{HHOT} * \mathrm{~L} 1-2 * \mathrm{R} * \mathrm{RHO} 02 * \mathrm{TCOL}+(6 * \mathrm{G} * \mathrm{H} * \mathrm{HCOLD} * \mathrm{HHOT} * \mathrm{~L} 1 * \mathrm{~L} 2+6 * \mathrm{G} * \mathrm{H} * \mathrm{HCOLD} * \mathrm{HHOT} * \mathrm{~L} 1-2) * \mathrm{M} \#$ $\mathrm{AIR} * \mathrm{RHO} 2+(-6 * \mathrm{G} * \mathrm{H} * \mathrm{HCOLD} * \mathrm{HHOT} * \mathrm{I} 1 * \mathrm{I} 2-6 * \mathrm{G} * \mathrm{H} * \mathrm{HCOLD} * \mathrm{HHOT} * \mathrm{I} 1 \sim 2) * \mathrm{MAIR} * \mathrm{RHO}) /(\mathrm{SQRT}(\mathrm{G}) * \mathrm{SQ} \#$ $\mathrm{RT}(\mathrm{H}) * \mathrm{SQRT}(\mathrm{L} 1) * \mathrm{SQRT}((\mathrm{L} 2+\mathrm{L} 1) * \mathrm{RHO} 2+(-\mathrm{I} 2-\mathrm{I} 1) * \mathrm{RHO}) *(((2 * \mathrm{SQRT}(2) * \mathrm{CP} * \mathrm{G} * \mathrm{HHOT}+2 * \mathrm{SQRT}(2 \#$ )$* \mathrm{CP} * \mathrm{G} * \mathrm{HCOLD}) * \mathrm{~K} * \mathrm{~L} 2+(2 * \mathrm{SQRT}(2) * \mathrm{CP} * \mathrm{G} * \mathrm{HHOT}+2 * \mathrm{SQRT}(2) * \mathrm{CP} * \mathrm{G} * \mathrm{HCOLD}) * \mathrm{~K} * \mathrm{~L} 1) * \mathrm{MAIR} * \mathrm{RHO} * \mathrm{R} \#$ $\mathrm{HO} 2+((-2 * \mathrm{SQRT}(2) * \mathrm{CP} * \mathrm{G} * \mathrm{HHOT}-2 * \mathrm{SQRT}(2) * \mathrm{CP} * \mathrm{G} * \mathrm{HCOLD}) * \mathrm{~K} * \mathrm{~L} 2+(-2 * \mathrm{SQRT}(2) * \mathrm{CP} * \mathrm{G} * \mathrm{HHOT}-2 * \#$ $\mathrm{SQRT}(2) * \mathrm{CP} * \mathrm{G} * \mathrm{HCOLD}) * \mathrm{~K} * \mathrm{~L} 1) * \mathrm{MAIR} * \mathrm{RHO}-2)+(12 * \mathrm{G} * \mathrm{HCOLD} * \mathrm{HHOT} * \mathrm{~L} 1 * \mathrm{~L} 2+12 * \mathrm{G} * \mathrm{HCOLD} * \mathrm{HHOT} * \mathrm{~L} \#$ 1-2)*MAIR*RHO2+(-12*G*HCOLD*HHOT*L1*I2-12*G*HCOLD*HHOT*L1-2)*MAIR*RHO)

In the above, the previous notations are capitalized. Thus $H$ is the zone height $h, G$ the acceleration of gravity $g, L 1$ the length of the left zone, etc...

This equation can be simplified by involing of various simplifiers from the MACSYMA functions. After simplification, the output is:

$\operatorname{SQRT}(2) * \mathrm{CP} * \mathrm{SQRT}(\mathrm{G}) * \mathrm{SQRT}(\mathrm{H}) * \mathrm{~K} * \mathrm{SQRT}(\mathrm{L} 1) *(\mathrm{~L} 2+\mathrm{L} 1) \sim(3 / 2) * \mathrm{R} * \mathrm{RHO} *(\mathrm{RHO} 2-\mathrm{RHO})-(3 / 2)$ $*(\mathrm{HHOT} * \mathrm{THOT}+\mathrm{HCOLD} * \mathrm{TCOLD})+6 * \mathrm{HCOLD} * \mathrm{HHOT} * \mathrm{~L} 1 * \mathrm{R} *(\mathrm{~L} 2 * \mathrm{RHO} 2-\mathrm{L} 2 * \mathrm{RHO}-\mathrm{I} 1 * \mathrm{RHO}) * \mathrm{THOT}$ $+6 * \mathrm{HCOLD} * \mathrm{HHOT} * \mathrm{~L} 1 \sim 2 * \mathrm{R} * \mathrm{RHO} 2 * \mathrm{TCOLD}=0$ 
which leads to the third order polynomial equation:

$2 * \mathrm{CP} \neg 2 * \mathrm{G} * \mathrm{H} * \mathrm{~K}\urcorner 2 * \mathrm{~L} 1 *(\mathrm{~L} 2+\mathrm{L} 1)-3 * \mathrm{RHO}$ - $2 *(\mathrm{RHO} 2-\mathrm{RHO})-3 *(\mathrm{HHOT} * \mathrm{THOT}+\mathrm{HCOLD} * \mathrm{TCOLD}) \frown 2-$ $(6 * \mathrm{HCOLD} * \mathrm{HHOT} * \mathrm{~L} 1 *(\mathrm{~L} 2 * \mathrm{RHO} 2-\mathrm{L} 2 * \mathrm{RHO}-\mathrm{L} 1 * \mathrm{RHO}) * \mathrm{THOT}+6 * \mathrm{HCOLD} * \mathrm{HHOT} * \mathrm{~L} 1 \sim 2 * \mathrm{RHO} 2 * \mathrm{TCOLD})-2$

This equation has the form $a x^{3}=(x-c)^{2}$ where $a$ and $c$ are positive, where $\mathrm{x}$ is $\rho_{2}-\rho$ the reduced cold zone air densitr; where

$$
c=\frac{l_{1}\left(T_{\text {hot }}-T_{\text {cold }}\right)}{l_{1} T_{\text {cold }}+l_{2} T_{\text {hot }}} \rho
$$

is proportional to the temperature difference. and where

$$
a=\frac{2 c_{p}^{2} g h k^{2}\left(l_{1}+l_{2}\right)^{3} \rho^{2}\left(h_{\text {hot }} T_{\text {hot }}+h_{\text {cold }} T_{\text {cold }}\right)^{2}}{36 h_{\text {cold }}^{2} h_{\text {hot }}^{2} l_{1}^{2}\left(l_{1} T_{\text {cold }}+l_{2} T_{\text {hot }}\right)^{2}}
$$

The order of magnitude of $c$ is $\frac{1}{300}$. and of $a$ is $510^{5}$.

It can be shown graphically that this 3 rd order equation has a real solution between 0 and $X$. where

$$
X=\frac{l_{1}\left(T_{\text {hot }}-T_{\text {cold }}\right)}{l_{1} T_{\text {cold }}+l_{2} T_{\text {hot }}} \rho
$$

Furthermore, we know that the solution can be expressed in closed form by radicals (since we are dealing with a 3rd order polynomial). Solving the equation using the following input values

[hhot=4, hcold=4., $h=3 ., 1=2 ., \quad 11=3 ., 12=3$, mair=0.029, $r=8.314$, rho=1.205, $c p=1004 ., g=9.81, k=0.83$, thot=303., $t \operatorname{cold}=283$.$] ;$

gives $1.206244948+28609$ as the value of the only one of three roots that is real. This is acceptable and expected (the air is denser on the cold side). Numerical back propagation (or substitution) of this symbolic solution to the other variables of interest leads to:

$$
\begin{aligned}
& \text { RHO2 }=1.206244948428609 \\
& \mathrm{RHO} 1=1.203755051571391 \\
& \mathrm{~T} 1=293.3027135161184 \\
& \mathrm{~T} 2=292.6972864838816 \\
& \mathrm{QMLOW}=0.3828828788442727 \\
& \mathrm{PHI}=232.7348756131578 \\
& \mathrm{P} 1=101219.9750313746 \\
& \mathrm{P} 2=101219.9750902376 \\
& \mathrm{P} 10=101237.6882869585 \\
& \mathrm{P} 20=101237.7249846537
\end{aligned}
$$

$\mathrm{Br}$ inspection we see that these results are reasonable. In particular, the middle pressures are equal, which is expected from the finding that the neutral point is exactly at mid height.

Comparison with a numerical solution of the same problem in slightly different units (degrees Celsius and reduced pressures instead of degrees tielvin and absolute pressures), using zonal models and the SPARI environment. yields 


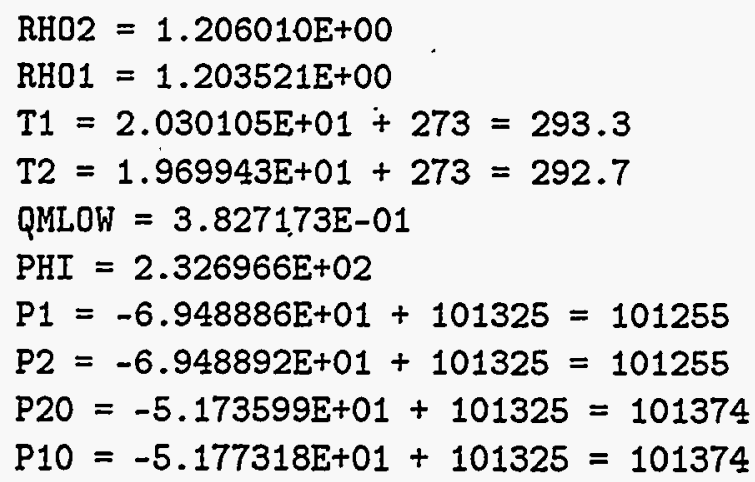

The agreement is uneven. The pressures differ by about 35 pascals. Howerer, the symbolic simulation assumes a perfectly tight room, which the numerical simulation does not.

Another (small) cause of discrepancy is that the power law used in the symbolic simulation is multiplied by a default density; whereas the numerical simulation uses the upstream density.

On the other hand, the temperatures, the mass flows and the heat transfers agree almost perfectly:

\subsubsection{Qualitative Observations in the Two-Zone case}

Qualitatively: we see that $\rho_{2}$ decreases when $a$ increases (i.e., when the height or permeability coefficient increases. or when the convective heat transfer at the wall decreases). On the other hand. $\rho_{2}$ increases when $c$ increases.

Also. we see that $\rho_{2}$ increases when the wall-to-wall temperature difference. $T_{\text {hot }}-T_{\text {cold }}$ : increases. This is because $c$ is proportional to $T_{\text {hot }}-T_{\text {cold }}$ and $a$ is slowly varying since it is the square of a homographic function.

Finally: since $a$ is large, it can be shown graphically that the physical root of $a x^{3}=$ $(x-c)^{2}$ is close to the root of $a x^{3}=c^{2}$. or $x=c^{2 / 3} a^{-1 / 3}$. This trend confirms and sharpens the above statements. For example. $\rho_{2}-\rho$ varies like $h^{-1 / 3}$.

\subsubsection{Global heat transfer in the two-zone case}

IFith computer algebra we automatically obtain the set of substitutions needed to calculate the other unknowns. The variable of interest. the global heat transfer, $\dot{\phi}$, is obtained from the following sequence of substitutions:

$\mathrm{PHI}=\mathrm{H} * \mathrm{HHOT} * \mathrm{~L} * \mathrm{THOT}-\mathrm{H} * \mathrm{HHOT} * \mathrm{~L} * \mathrm{~T} 1$

QMSUP = QMLOW

$\mathrm{T} 1=($ HHOT $* \mathrm{THOT}+\mathrm{HCOLD} * \mathrm{TCOLD}-\mathrm{HCOLD} * \mathrm{~T} 2) / \mathrm{HHOT}$

$\mathrm{T} 2=(\mathrm{CP} * \mathrm{HHOT} * \mathrm{QMLOW} * \mathrm{THOT}+(\mathrm{CP} * \mathrm{HCOLD} * \mathrm{QMLOW}+\mathrm{H} * \mathrm{HCOLD} * \mathrm{HH} O \mathrm{~T} * \mathrm{~L}) * \mathrm{TCOLD}) /((\mathrm{CP} * \mathrm{HHOT}+\mathrm{CP} * \mathrm{H} \#$ COLD) $*$ QMLOW+H*HCOLD*HHOT*L)

$\mathrm{QMLOW}=-(2 * \mathrm{SQRT}(\mathrm{G}) * \mathrm{~K} * \mathrm{~L} * \mathrm{RHO} * \mathrm{SQRT}(\mathrm{RHO2}-\mathrm{RHO} 1) * \mathrm{SQRT}(\mathrm{H}-\mathrm{ZN}) * \mathrm{ZN}-2 * \mathrm{SQRT}(\mathrm{G}) * \mathrm{H} * \mathrm{~K} * \mathrm{~L} * \mathrm{RHO} * \#$ $\operatorname{SQRT}(\mathrm{RHO} 2-\mathrm{RHO} 1) * \mathrm{SQRT}(\mathrm{H}-\mathrm{ZN})) / 3$

$\mathrm{ZN}=\mathrm{H} / 2$

$\mathrm{RHO} 1=-(\mathrm{I} 2 * \mathrm{RHO} 2+(-\mathrm{L} 2-\mathrm{L} 1) * \mathrm{RHO}) / \mathrm{L} 1$

We note that the neutral point for this simple case is always at mid height. The final equation for $\dot{0}$ is: 
$\mathrm{PHI}=\mathrm{H} * \mathrm{HHOT} * \mathrm{I} * \mathrm{THOT}-\mathrm{H} * \mathrm{I} *\left(-\mathrm{HCOLD} *\left(\mathrm{CP} * \mathrm{SQRT}(\mathrm{G}) * \mathrm{H}^{-}(3 / 2) * \mathrm{HHOT} * \mathrm{~K} * \mathrm{I} * \mathrm{RHO} * \mathrm{SQRT}((\#\right.\right.$ $\mathrm{L} 2 * \mathrm{RHO} 2+(-\mathrm{L} 2-\mathrm{L} 1) * \mathrm{RHO}) / \mathrm{I} 1+\mathrm{RHO} 2) * \mathrm{THOT} /(3 * \mathrm{SQRT}(2))+\left(\mathrm{CP} * \mathrm{SQRT}(\mathrm{G}) * \mathrm{H}^{\sim}(3 / 2) * \mathrm{HCOLD} * \mathrm{~K} * \mathrm{~L} * \#\right.$ $\mathrm{RHO} * \mathrm{SQRT}((\mathrm{L} 2 * \mathrm{RHO} 2+(-\mathrm{L} 2-\mathrm{I} 1) * \mathrm{RHO}) / \mathrm{L} 1+\mathrm{RHO} 2) /(3 * \mathrm{SQRT}(2))+\mathrm{H} * \mathrm{HCOLD} * \mathrm{HHOT} * \mathrm{~L}) * \mathrm{TCOLD}) /(\mathrm{S} \#$ $\mathrm{QRT}(\mathrm{G}) * \mathrm{H}^{-}(3 / 2) *(\mathrm{CP} * \mathrm{HHOT}+\mathrm{CP} * \mathrm{HCOLD}) * \mathrm{~K} * \mathrm{~L} * \mathrm{RHO} * \mathrm{SQRT}((\mathrm{L} 2 * \mathrm{RHO} 2+(-\mathrm{L} 2-\mathrm{L} 1) * \mathrm{RHO}) / \mathrm{L} 1+\mathrm{RHO} 2) \#$ $/(3 * \mathrm{SQRT}(2))+\mathrm{H} * \mathrm{HCOLD} * \mathrm{HHOT} * \mathrm{~L})+\mathrm{HHOT} * \mathrm{THOT}+\mathrm{HCOLD} * \mathrm{TCOLD})$

The ratio $\mathcal{N} u$ (Nusselt number) of $\dot{\phi}$ to the purely conductive flux

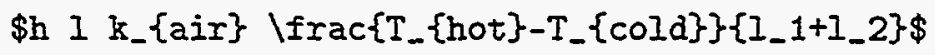

is

SQRT(G) SQRT(H) (CP HCOLD HHOT K L2 + CP HCOLD HHOT K L1) RHO

$\operatorname{SQRT}((\mathrm{L} 2+\mathrm{L} 1) \mathrm{RHO} 2+(-\mathrm{L} 2-\mathrm{L} 1) \mathrm{RHO})$

$/(\mathrm{SQRT}$ (G) SQRT(H) (CP HHOT + CP HCOLD) K KAIR RHO

SQRT((L2 + L1) RHO2 + (- I2 - I1) RHO) + 3 SQRT(2) HCOLD HHOT KAIR SQRT(L1))

This is a rational function in $\sqrt{\rho_{2}-\rho}$. Further simplification leads to:

$$
N u=\frac{\frac{l_{1}+l_{2}}{k_{\text {air }}}}{\left(\frac{1}{h_{h o t}}+\frac{1}{h_{c o l d}}\right)+\frac{3 \sqrt{2} \sqrt{\frac{l_{1}}{l_{1}+l_{2}}}}{c_{p} \sqrt{g h k} \frac{1}{\rho \sqrt{\rho_{2}-\rho}}}}
$$

For the problem under consideration we obtain

$$
N u=\frac{1}{0.0021+\frac{0.0000023}{\sqrt{\rho_{2}-1.205}}}
$$

which is about 46.5 .

He see that the larger value of $\rho_{2}$ (due. for example. to an increase in temperature difference). produces a larger value of $N u$.

\subsubsection{Comparison of the Two-Zone Case with Theory}

In laminar natural convection (see [Bej84], for example), $\lambda u$ depends on the Rayleigh number. $R a_{h}$. according to $N u=0.364 \frac{l_{1}+l_{2}}{h} R a_{h}{ }^{1 / 4}$. A rough evaluation using $R a_{h}=$ $107000000 h^{3} \Delta T=57780000000$, an approximation valid at those temperatures, yields $\therefore u=356$. Thus. $\$ u$ increases as $h^{3 / 4}$ and as $\Delta T^{1 / 4}$. For turbulent natural convection $\Lambda u$ varies as $\Delta T^{1 / 3}$ since $\lambda u=0.065 G r_{h}^{1 / 3}\left(\frac{h}{l_{1}+l_{2}}\right)^{-1 / 9}$ according to the Jakob correlation. Numerical application to our problem yields $\aleph^{i} u=304$.

Thus, the coarse-grained two-zone zonal model overestimates the ratio of convective to conductive heat transfer by 30 to $50 \%$.

The zonal model applied to two continuous zones exhibits a qualitatively appropriate behavior: an increase in $h$ or $\Delta T$ does increase $N u$ if the other parameters are held constant.

IVe should also take into account the temperature dependence of the wall heat transfer coefficients. $h_{\text {hot }}$ and $h_{\text {cold }}$, to better account for the temperature dependence of $N u$. Nu depends on the harmonic mean of the wall heat transfer coefficients, which, in turn, go as $R a^{1 / 4}$. Thus. the qualitative behavior of the zonal model. even in the simple two-zone case. is consistent with the theoretical and experimental natural convection if the wall heat transfer coefficients are chosen appropriately. 


\subsubsection{Two-Zone Case with Inlet Air}

A generalization of the two-zone problem is to allow air to flow in (at the left. for example) at a specified rate. Assuming that circulation still exists. i.e., that the inlet flow is small enough not to disturb the flow pattern. we can again reduce the overall system to two equations in unknowns $\rho_{2}$ and $z_{n}$. One equation is a second-order polynomial in $\sqrt{\rho_{2}-\rho}$ that can be eliminated by solving for $\rho_{2}$. leaving a single equation in $z_{n}$. However. this equation contains large, nonpolynomial expressions. Thus little can be said on the parameter dependency of its solutions, unlike in the previous case.

\section{Numerical Implementation: the SPARK Envi- ronment}

\subsection{Presentation and History}

The Simulation Problem Analysis and Research Kernel (SPARK) is a modular environment that automates writing code for systems of nonlinear equations. It was developed for building science but is applicable to other fields. It is related to simulation environments like TI!'Solver [K.J85]. TRNSYS [Sol88], CLIMI2000 [BC.GR89], IDA [Sah88]. and Allan.Simulation [Fra92].

Some kev features of SPARIi are:

- It has a front end that allows the user to build complex simulations by connecting smaller elements that are objects (single equations) or macro-objects (equation subsystems). It shares this feature with TRASYS, CLIM2000 and Allan.Simulation.

- Csing graph-theoretic techniques, it reduces the size of the equation system by automatically determining a small set of iteration variables for which the other unknowns can be solved. This step can be viewed as "smart" elimination of variables. SPARH"s lewton-Raphson solver works on the reduced equation set and, after convergence. the remaining unknowns are solved for. This is a unique feature. Allan.Simulation. for example. generates code that inverts the full Jacobian matrix.

- Its output is a C program that is automatically compiled and executed. This program accepts user-specified input at run time and is calculationally efficient because it iterates on a reduced set of variables.

- Passing from a simulation problem to a design problem (i.e., haxing unknowns become inputs and inputs become unknowns) is simply a matter of keyword exchange in SPARK.

Originally written in 1986 for steady state problems [And87], it was extended in 1989 to handle transient problems by adding time integrator objects [SBNi89]. Recent enhancements include

- Automatic generation of objects from equations expressed symbolically ( [S:Th:90]. [AW94]).

- Strong component decomposition to reduce execution time $\left[\mathrm{BEN}^{+} 93\right]$.

- Viser control of solution method to enhance convergence. 


\subsection{Implementation of the Zonal Model}

Implementation of zonal models in SPARI is straightforward. The main object classes correspond to the zones and to the interfaces between zones. A zone class consists of the balance equations for the zone, the pressure drop equation and the perfect gas law. An interface class consists of the neutral point calculation and the relationship between mass flow and pressure difference.

These classes are instantiated as many times as needed to define the simulation. For example. if a 3-D room is divided into eight parallelopipeds (two in each of the $x, y$ and $z$ directions). there will be eight zone objects and 36 interface objects (12 zone-to-zone interfaces and 24 zone-to-surface interfaces). In the general 3-D case, if the $x, y$ and $z$ axes are divided into $L . M$ and $N$ sections. respectively. there will be $L M N$ zone objects and $3(L M+M N+L M)$ interface objects. In 2 -D there will be $L M$ zone objects and $L M I$ zone-to-zone interface objects and $2 L M$ zone-to-surface interface objects.

After instantiation. the objects are linked, i.e.. the variables shared by objects are indentified. Then the objects and their linked variables are stored in a file that specifies the overall problem and its inputs.

\subsection{Efficiency}

The efficiency of a simulation environment depends on the time and resources needed to solve a simulation problem. SPART obtains a near-optimal simplification of the problem. without loss of precision. by automatically reducing the number of iteration variables. The reduction can be more than 10 -fold. which corresponds to a roughly 1000 -fold decrease in Jacobian inversion time. SPARK also makes it easy to create a simulation from scratch by using strmbolic processing to create the simulation building blocks (equation objects) from equations written by the user [AW94]. In the present work even the linking of objects was automated ([NW93].[Wur95]).

To facilitate interpretation of results: a graphical postprocessor was written to visualize temperatures and air flows.

\section{The 2-D "window" Problem}

\subsection{Description}

A 2-D. $6 \mathrm{~m} \times 2.4 \mathrm{~m}$ shallow enclosure has its left wall maintained at $12 \mathrm{C}$, its right wall at $20 \mathrm{C}$. and its floor and ceiling at $15 \mathrm{C}$. The surface heat transfer is assumed to be linear in surface-to-air temperature difference, with convective heat transfer coefficient, $h$, of 4.1 . 1.0 and $5.1 \mathrm{Wm}^{-1} \mathrm{~K}^{-1}$ at the walls, floor and ceiling, respectively [Ina88]).

Two different grids were used for the zonal model, $3 \times 3$ and $6 \times 6$, which yield 108 and 432 equations. respectively: After reduction in SPARK, there were 18 and 72 equations. respectively. The iteration variables chosen were the temperature and midpoint pressure of each zone.

\subsection{Numerical Validation}

The calculated flow field is shown qualitatively in Figure 1. The expected circulation pattern is observed, i.e., downward flow across the cold wall and upward flow across the 


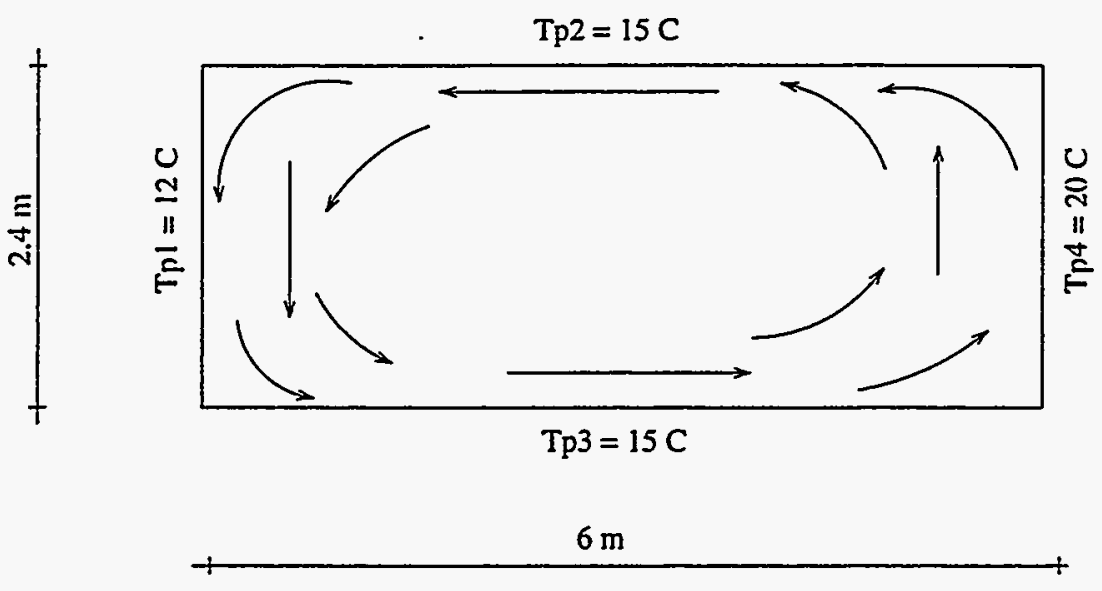

Figure 1: Natural conrectire flow in the 2-D "window" model

warm wall. The results were compared to runs using the CFD code Fluent [Ina88], which is based on the finite volume method and uses uniform gridding. logarithmic velocity profiles near surfaces. and the $k-\epsilon$ turbulence model.

Figures 2 and 3 show that the air temperatures for the zonal and CFD models are similar. The maximum difference between the models is $8 \%$ along the mid-room horizontal axis and $10 \%$ along the mid-room vertical axis.

The zonal model's temperature distribution is more "conductive" than the C.FD distribution because the zonal model is diffusive (assumes perfect mixing) and ignores thermal boundary layers.

The agreement between the air flow velocity results (Figures 4 and 5 ) is less satisfactory than for the tempratures but still acceptable.

The error is above $10 \%$ close to the floor and ceiling. Again. the zonal model does less well close to the walls since it does not account for boundary layer effects.

\subsection{Sensitivity Analysis}

Wie see that changing the grid from $3 \times 3$ to $6 \times 6$ in the window problem barely changes the results. which indicates that a coarse grid is adequate.

We also tested the sensitivity of the model to the permeability coefficient. $C$. and to the wall heat transfer coefficients, $h$. The results are given in Figures 6 and 7 . which show how the temperature distribution changes with $C$, and in Figure 8 , which shows how the velocity. distribution changes with $C$. We see that air temperature and velocity are fairly insensitive to $C$ and that the best results are obtained with the commonly accepted value of 0.83 [FGG89].

Wie also found that the results are insensitive to $h$ (not shown). We conclude that a zonal model with coarse gridding gives acceptable results for the 2-D window problem even with uncertainties in the values of permeability and surface heat transfer coefficients. 


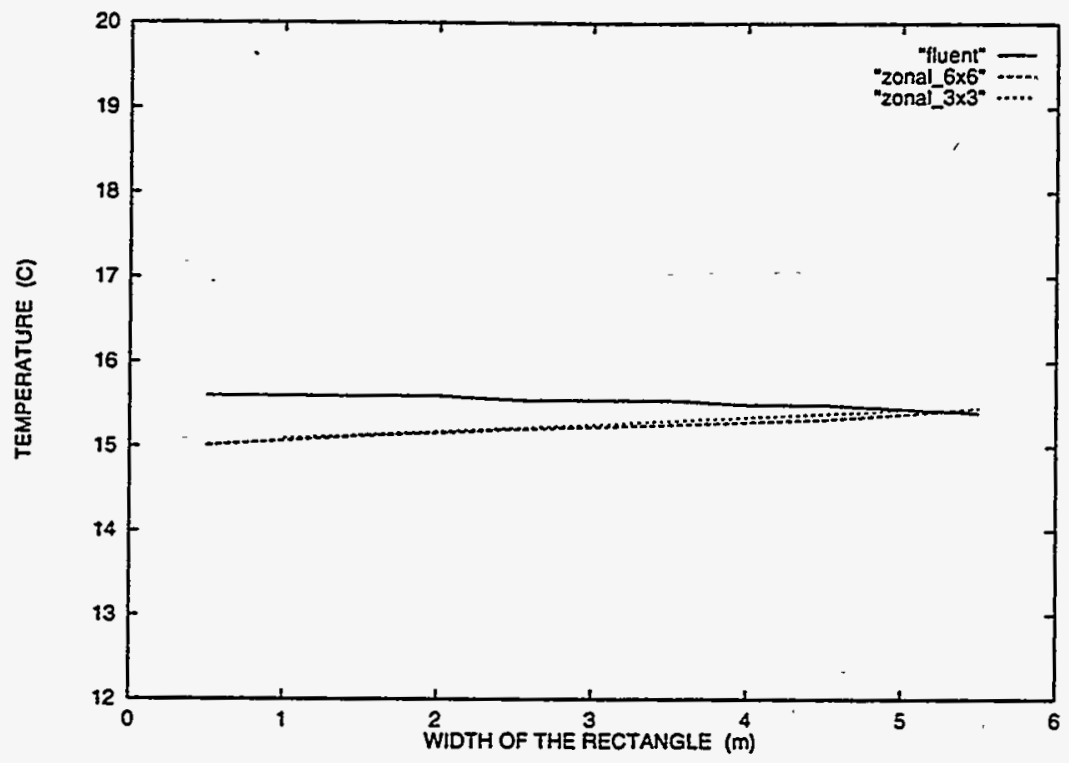

Figure 2: 2-D "window" problem: horizontal distribution of air temperature at mid-height predicted by the zonal model (for $3 \times 3$ and $6 \times 6$ griclding) and the Fluent CFD calculation.

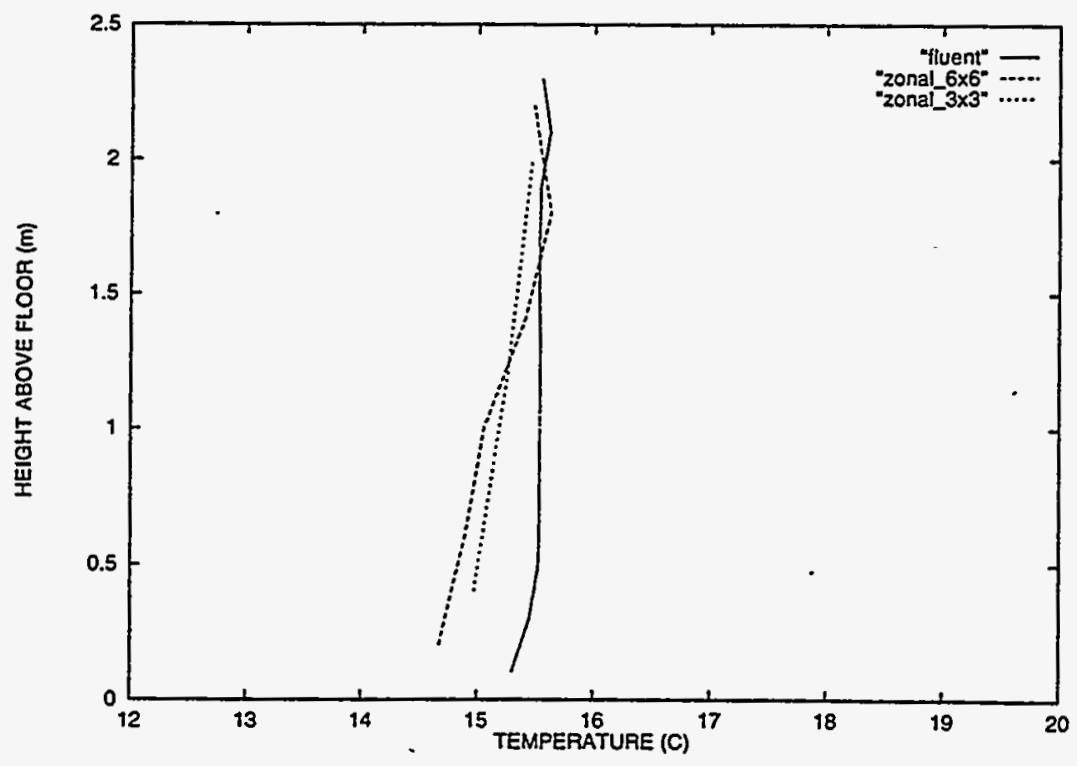

Figure 3: 2-D "window" problem: vertical distribution of air temperature at mid-room predicted br the zonal model (for $3 \times 3$ and $6 \times 6$ gridding) and the Fluent CFD calculation 


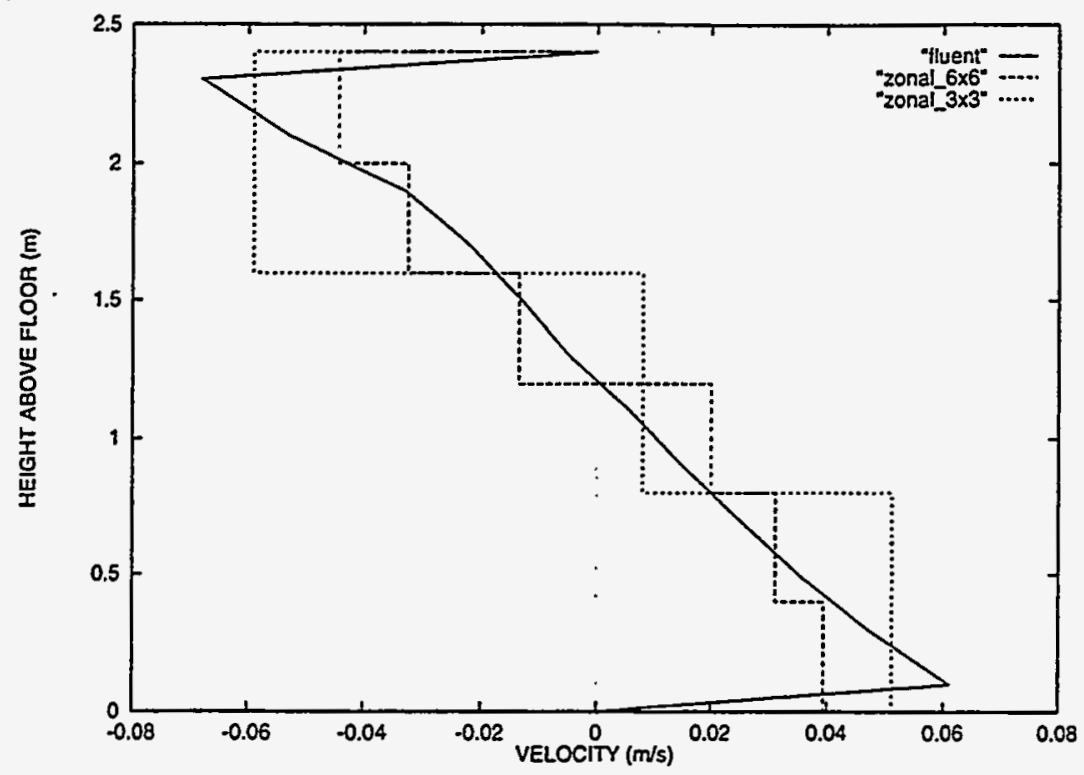

Figure 4: 2-D "window" problem: vertical distribution of horizontal air velocity predicted by the zonal model (for $3 \times 3$ and $6 \times 6$ gridding) and the Fluent CFD calculation

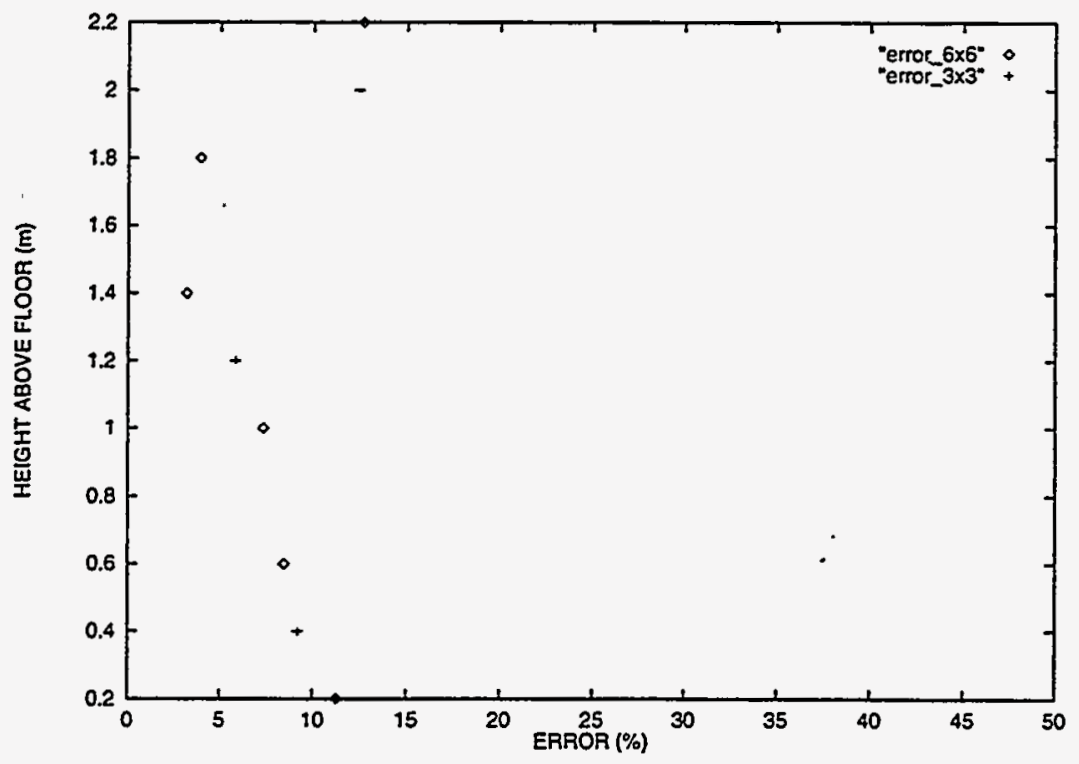

Figure 5: 2-D "window" problem: percent difference in horizontal air flow velocity vs. height above floor between zonal model (for $3 \times 3$ and $6 \times 6$ gridding) and Fluent C.FD calculation 




Figure 6: 2D "window problem": Sensitivity to permeability coefficient of the horizontal distribution of air temperature as determined by the zonal model. The prediction of the Fluent CFD model is shown for comparison.

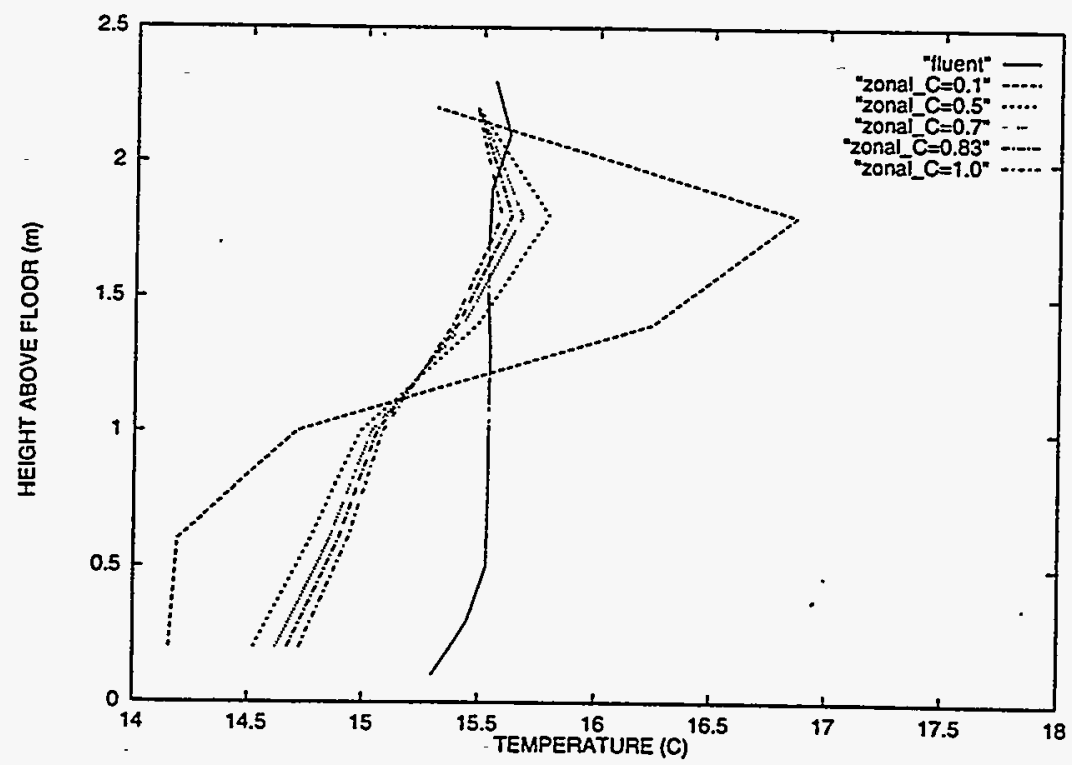

Figure i: 2D "window problem": Sensitivity to permeability coefficient of the vertical distribution of air temperature as determined by the zonal model. The prediction of the Fluent CDF model is shown for comparison. 


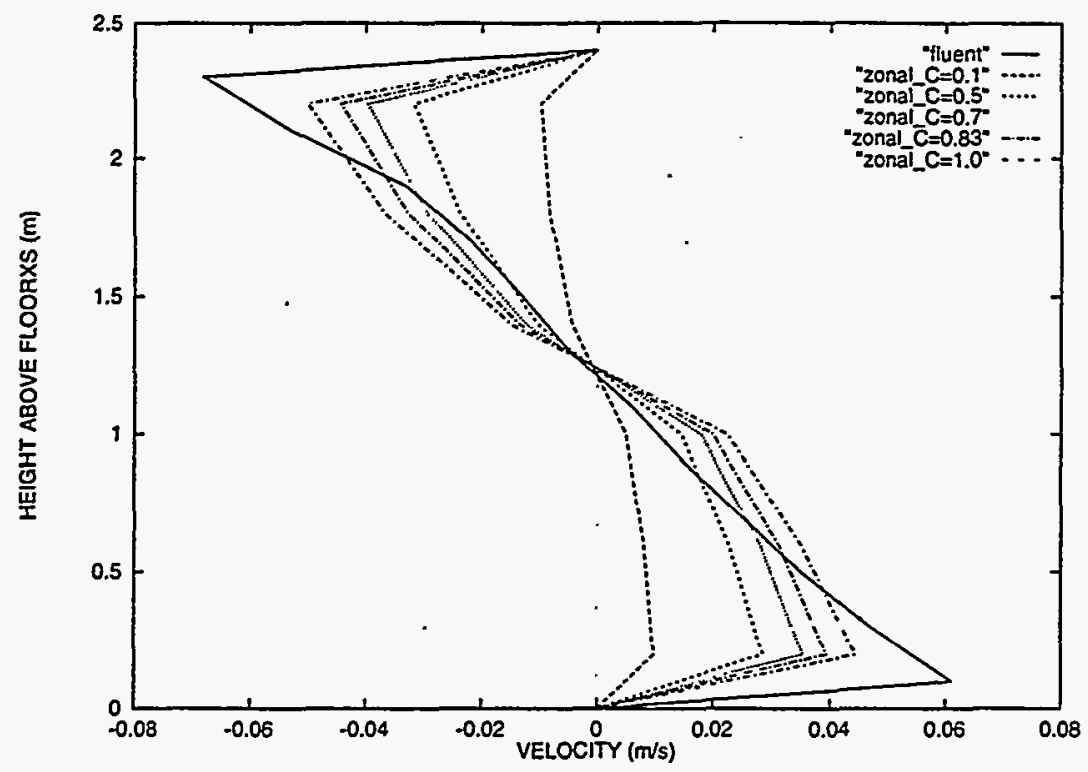

Figure S: 2D "window problem": Sensitivity to permeability coefficient of the horizontal distrjbution of rertical air velocity. The prediction of the Fluent CFD model is shown for comparison.

\section{The 3-D Parallelopiped}

\subsection{Description}

A 3-D. $2.6 \mathrm{~m} \times 3.6 \mathrm{~m} \times 2.55 \mathrm{~m}$, cell has the left wall maintained at $25.5 \mathrm{C}$, the right wall at $32 \mathrm{C}$. the ceiling at $26 \mathrm{C}$ and the other walls at $24.5 \mathrm{C}$. The convective heat transfer coefficients at the walls are the same as in the $2-D$ case.

Vie chose a grid that was $4 \times 4 \times 4$, which produced 2240 equations. With an exponent of 1 in the mass flow equations. SPART reduced this to 128 equations (a 16 to 1 reduction). Convergence was achieved with a Newton-Raphson relaxation coefficient of 0.5 , and by choosing initials values that were close to the final solution.

\subsection{Validation}

The zonal model results were validated numerically and by comparing with experimental results. Numerical validation was done using the Fluent CFD code. A temperature comparison is shown in Figures 9 and 10 and a velocity comparison in Figure 11. The zonal model temperatures are close to the CFD results, and lie between the C.FD and measured values. The largest difference between zonal model and measurements, which is about $2 \mathrm{C}$, occurs near the floor, where the air is cooler and diffusion is smaller. As expected, the difference between the zonal model and measured air velocity is largest near the walls. We found better agreement (not shown) by using smaller zones near the walls. 


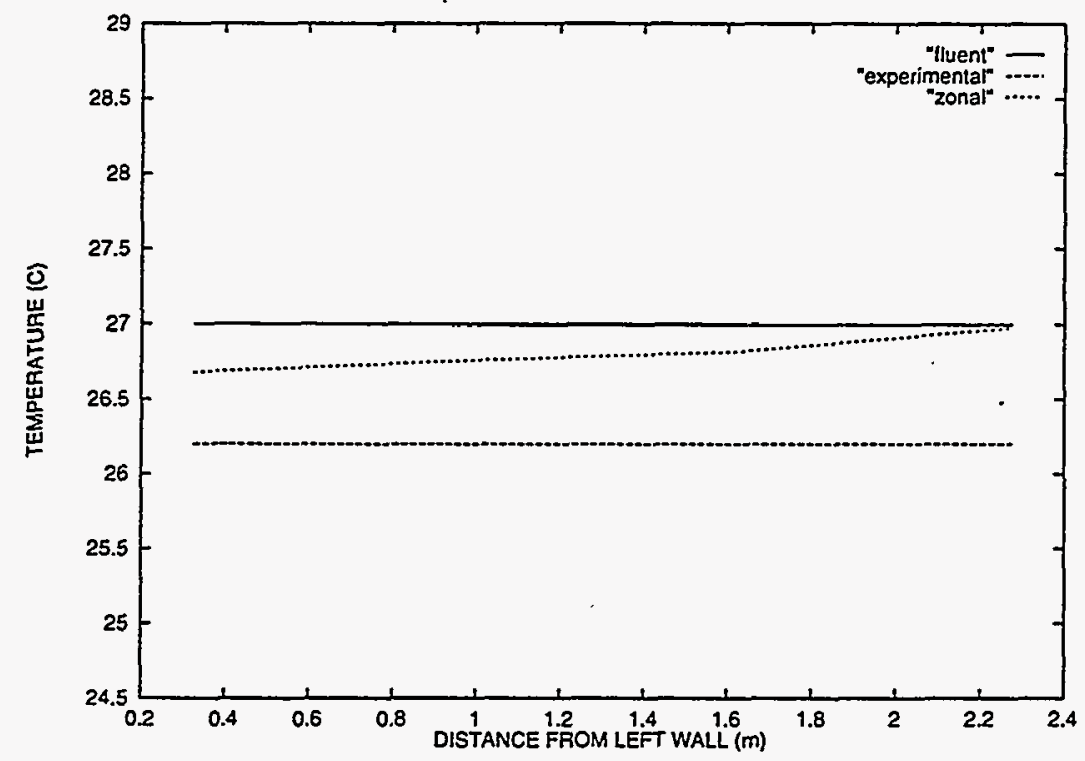

Figure 9: Comparison of the measured horizontal distribution of the air temperature at midheight with the predictions of the 3-D zonal model and the Fluent C.FD calculation.

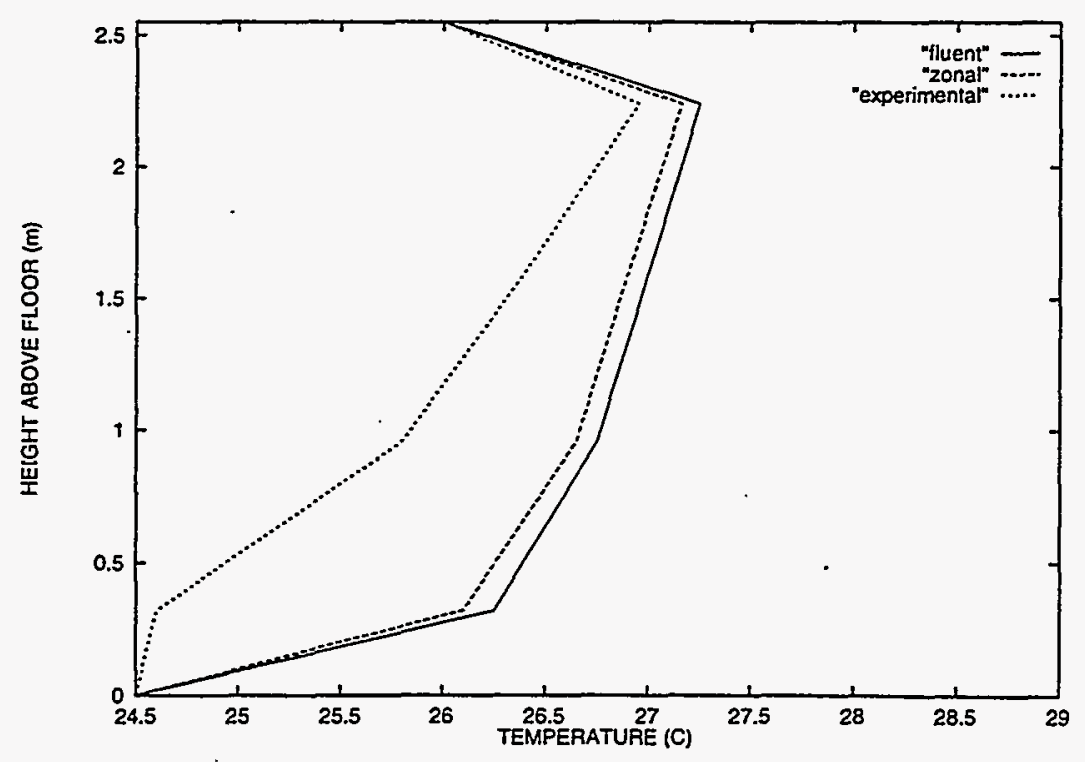

Figure 10: Comparison of the measured vertical distribution of air temperature at room center with the predictions of the 3-D zonal model and the Fluent CFD calculation. 


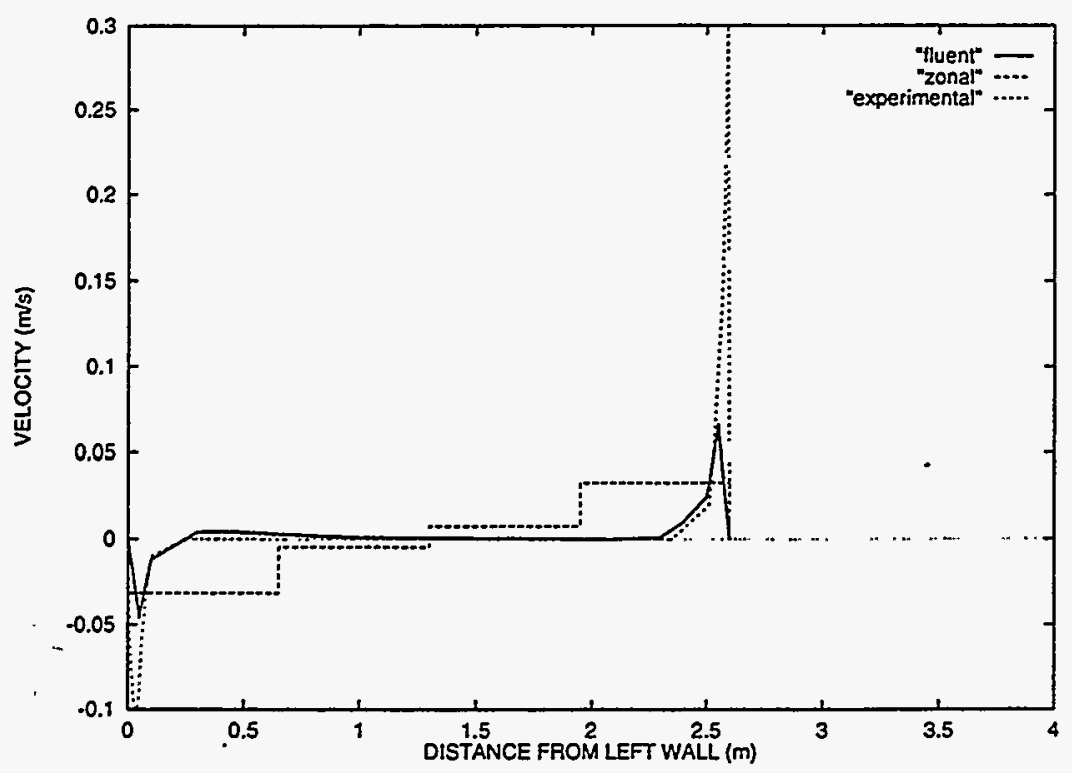

Figure 11: Comparison of the measured horizontal distribution of the rertical air relocity at mid-height with predictions of the zonal model and the Fluent CFD calculation.

\section{The Minibat Cell}

\subsection{Presentation of the Problem}

To test the zonal approach on a more complex problem. we modeled the "Minibat Cell." a test struct ure at INSA (Institut National des Sciences Appliquées) in Toulouse. France. This $6.2 \mathrm{~m} \times 3.1 \mathrm{~m} \times 2.5 \mathrm{~m}$ cell is divided into a warm room and a cold room by a partition that has a $0.7 \mathrm{im}$ wide by $1.83 \mathrm{~m}$ high open doorway: The left wall is maintained at $28.0 \mathrm{C}$. the right wall at $22.5 \mathrm{C}$. the ceiling at $25.0 \mathrm{C}$ on the warm side and $24.81 \mathrm{C}$ on the cold side. the floor at $24.58 \mathrm{C}$ and the other walls at $24.63 \mathrm{C}$.

We used a $6 \times 3 \times 6$ grid, which led to $3 i+4$ equations. SPARK reduced this to 216 equations (a $1 \mathrm{i}$ to 1 reuction).

\subsection{Validation}

The air temperature distributions calculated by the zonal model on the warm and cold sides are shown in Figures 12 and 13. The air velocity distibution in the doorway is shown in Figure 14. For comparison, these figures also show measured data and the predictions of the StarC'D C'FD program, which is based on a finite-rolume method.

The zonal model's temperature results are satisfactory. They fall, for the most part. between the measured and the C:FD values. As in the previous test case, the highest discrepancy occurs near the floor. The overall agreement with measured and CFD results is somewhat better on the warm side of the cell.

The zonal model correctly predicts the qualitative behavior of the air flow in the doorway. but. quantitatively, there are differences up to $25 \%$ relative to the measurements. Flows are generally overestimated in the doorway. although the neutral point is correctly. calculated. This indicates that better agreement would be obtained by reducing the permeability coefficient in the opening [LIA.91] 


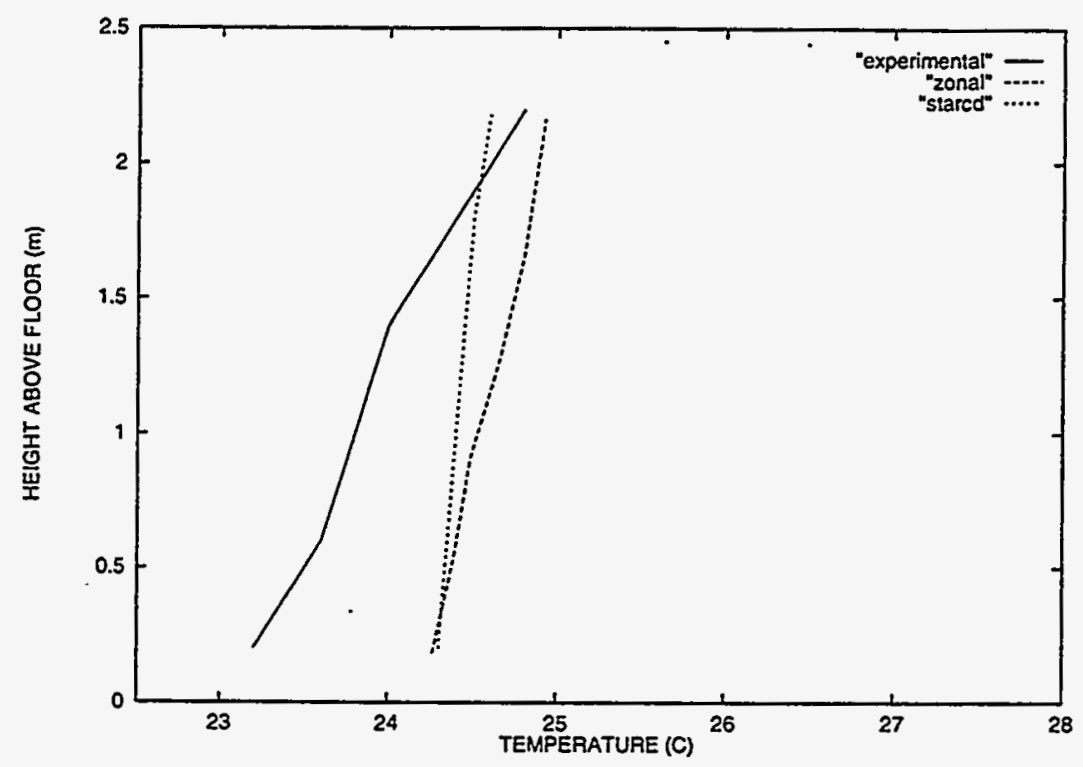

Figure 12: Comparison of the measured vertical distribution of air temperature on the cold side of the Minibat cell with predictions of the zonal model and the StarCD CFD calculation.

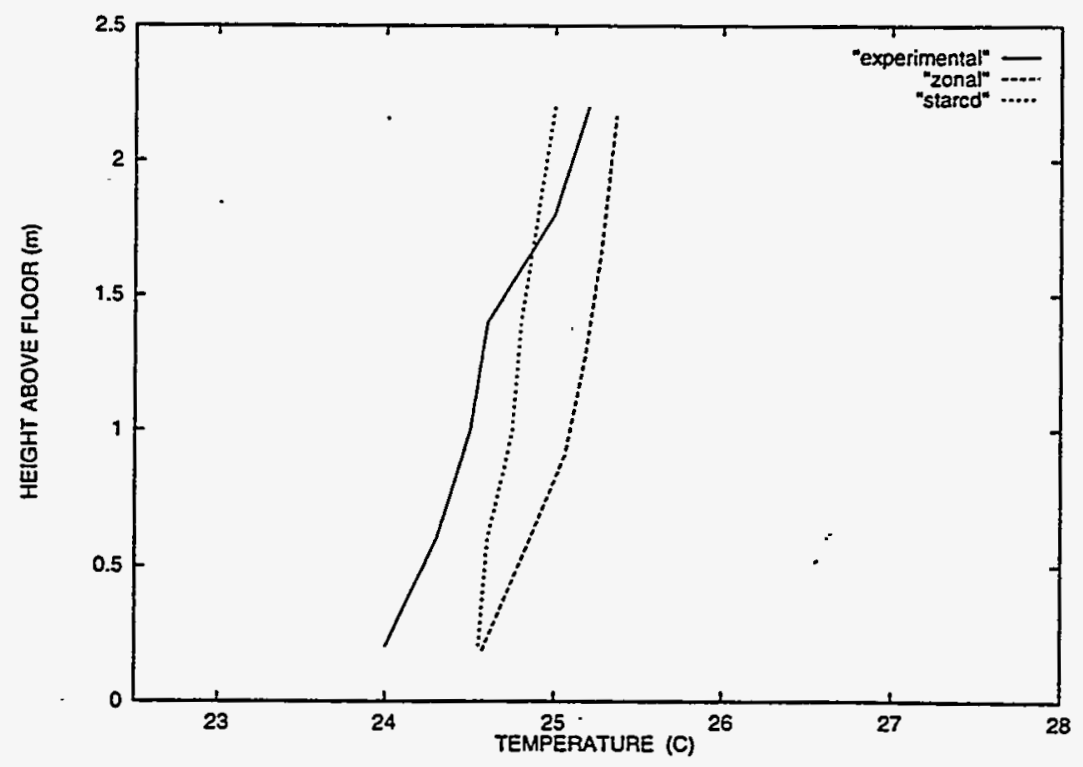

Figure 13: Comparison of the measured vertical distribution of air temperature on the warm side of the Minibat cell with predictions of the zonal model and the StarCD CFD calculation. 


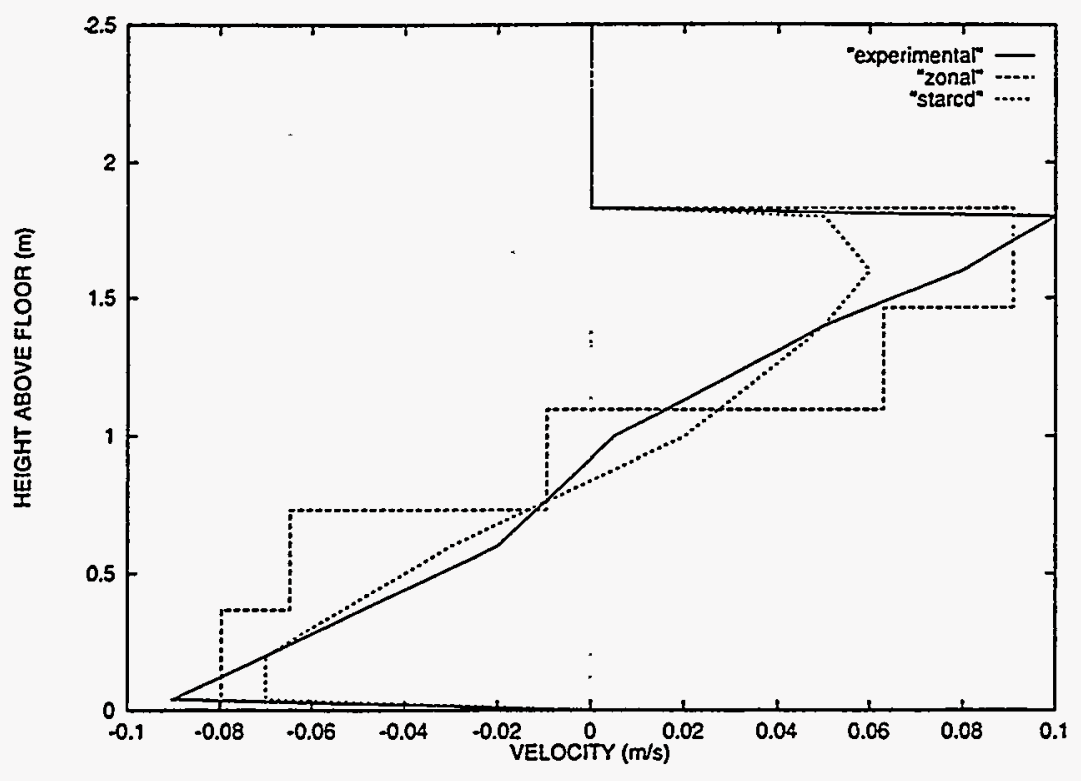

Figure 14: Comparison of the measured rertical distribution of horizontal air velocity in the doorway of the Minibat cell with predictions of the zonal model and the StarCD CFD calculation. Air moring from right to left (from the cold sicle to the warm side) is considered to have positive relocity:

\section{Coupling to External Models}

Having demonstrated the overall reliability of zonal models, at least for simple rectangular geomotries. we demonstrate in this section modularity and reusability in object-based simulation by coupling the zonal model with a comfort model.

\subsection{Comfort model}

We consider a simple. classsic comfort model-the Fanger model [Fani3]- which is expressed as

$$
\begin{gathered}
C T=H-E-R-C \\
P . M V=\left[0.303 e^{-0.036 M}+0.028\right] \times C T
\end{gathered}
$$

Here. $C ' T$ is the state of thermal comfort, which is determined by occupant activity level. $H$. evaporation rate, $E$. radiative heat loss, $R$. and convective heat loss, $C$. PMV is the predicted mean vote, for which a zero value of 0 corresponds to feeling comfortable, a positive value to feeling too warm and a negative value to feeling too cold.

Because of the modularity of the SPARK environment, all that was needed to couple the comfort and zonal models was to add the Fanger equations to the zone equations. The results of solving the resulting equation sét for the Minibat Cell are shown in Figure 1.5.

\subsection{Wall-to-Air coupling}

Air flow models should be coupled to realistic wall models. The modularity of the SPARI object-based approach allows wall models to be easily created using the "modal" method 


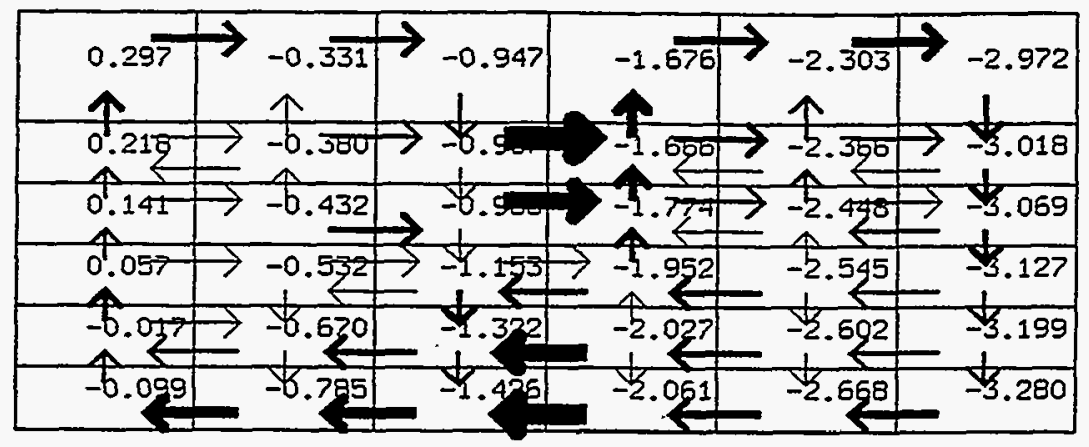

Figure 15: Comfort analysis based on coupling of Fanger model and zonal model: Predicted Mean Vote in rertical-midplane zones of the Minibat Cell. The arrows show air flow between zones.

[FBST91]. In this method the conduction equations for complex geometries are solved in full and the significant modes are determined. This reduces the complexity of the model with little loss of accuracy.

We incorporated the wall conduction flux from the modal approach into the general energy balance equation for the air zones adjacent to the walls. Given the external conditions. the SPARK solver then determined the surface temperatures as well as the distributions of inside air temperature and air flow.

\subsection{Coupling to a Hydronic Cooling System}

The zonal model was also coupled to an independently developed SPARK simulation of a hydronic radiant cooling system in which the heat transfer to the room air was originally: modeled assuming a single air node, i.e., assuming a uniform air temperature [CSW95]. This coupling was accomplished in a straightforward fashion and led to a more accurate model in which the heat transfer from the cooled surfaces to the air took into account the spatial variation of air temperature.

\subsection{Coupling to Plumes and Jets}

The main weakness of zonal models is that they cannot properly represent air jets (from diffusers. for example) or plumes (which are common around heaters), since in these models jets and plumes are (incorrectly) assumed to be fully dissipated in the zone in which they originate. One way around this limitation is to replace zones that contain a jet or plume with a specific jet or plume object. To investigate this possibility we considered the case of a $3-\mathrm{D} 4.75 \mathrm{~m} \times 3 \mathrm{~m} \times 2.5 \mathrm{~m}$ room that had a heater next to a cold wall. A $6 \times 6 \times 4$ grid was used in which the zonal models for the three zones above the heater were replaced with a plume object. We found in this case that a pure zonal model without a plume object gave unacceptable results (for example, there was an unphysical horizontal diffusion immediately above the heater). However, when a plume object was used a physically reasonable air flow pattern was observed. 


\section{Conclusion and Perspectives}

We have shown that for simple rectangular geometries, the zonal method gives reasonably accurate air flow and air temperature results even in 3-D cases (for which convergence problems are usually encountered when other methods are used). Zonal models are easier to incorporate in modular simulation environments than are C.DF models and are much faster executing. However. further work is needed to establish guidelines for optimal partitioning of rooms into zones. In particular, it should be determined whether partitioning can or should be based on the expected flow pattern. Additional effort is also needed to improve the modeling of jets and plumes. It would also be of interest to extend the zonal method to consider moisture and pollutant transport.

\section{Acknowledgements}

This work was partially supported by the Assistant Secretary for Energy Efficiency and Renewable Energy: Office of Building Technologies, Building Systems and Materials Division of the T.S. Dept. of Energy; under contract Xo. DE-AC03-i6SF00098.

\section{References}

[AndSi] J. L. Anderson. A network definition and solution of simulation problems. Technical Report 21522. Lawrence Berkeley Laboratory; Berkeley: CA 94i20. September $198 \pi$.

[BC'GR89] D. Bomneau, D. Covalet, D. Gautier. and F.X. Rongere. Manuel de Prise $\epsilon n$ Main. C:LIMIO000. lérsion 0.0, 1989.

[BD91] H. Bouia and P. Dalicieux. Simplified modelling of air movements inside dwelling room. In Proc. of the Building Simulation 91 conference. August 1991.

[BejS4] A. Bejan. Conrection Heat Transfer. A Wilhey-Interscience Publication. 1984.

[BE. ${ }^{+9}$ 93] Fred Buhl, Ender Erdem, Jean-Nichel Nataf. Frederick Winkelmann, and Edward Sowell. Recent improvements in spark: Strong component decomposition. multivalued objects and graphical interface. LBL Report LBL-33906. Lawrence Berkeley Laboratory. August 1993.

[BGIFG8] Fred Bauman, Ashok Gadgil, Ronald Iiammerud, and Ralph Greif. Buoyancy-driven convection in a rectangular enclosure: experimental results and numerical calculations. Technical Report LBL-10257, Lawrence Berkeley Laboratory; July 1980.

[BNIS91] G.S. Barozzi. E. Nobile. M. S. Imbabi, and A. C. M. Sousa. Scale models and cfd for the analysis of air flow in passively ventilated buildings. In Proceedings of Building Simulation "91. Sophia-Antipolis. Nice, France, pages 118-124. International Building Performance Simulation Association, 20-22 August 1991.

[CC.95] J.A. Clarke. W. M. Cempster. and C. Negrao. The implementation of a computational fluid dynamics algorithm within the esp-r system. In Proceedings 
of Building Simulation :95. Madison. Wisconsin. pages 166-175. International Building Performance Sinulation Association. August 14-16 1995.

[CE;G] C. C. Chen and R. Eichhorn. Natural convection from a vertical surface to a thermally stratified fluid. Journal of Heat Transfer. pages 446-451. August 1976.

[CSW:95] Helmut E. Feustel Corina Stetiu and Frederick C. Winkelmann. Development of a simulation tool to evaluate the performance of radiant cooling ceilings. LBL and C.IEE Report LBL-37300. LiC-1600, Lawrence Berkeley Laboratory. June 1995.

[Dav82] G. De Vahl Davis. Natural convection of air in a square cavity: a benchmark solution. Technical Report 1982;F:IT/2. School of Mechanical and Industrial Engineering; Unir. South Wales, 1982.

[Dav8:3] G. De Vahl Davis. Natural convection of air in a square carity: a bench mark numerical solution. International journal for numerical methods in fiuids. 3:249-264, 1983.

[F.AS9] Helmut E. Feustel and Al. The comis infiltration model. In Procetdings of Building Simulation 89, Vancouver, June 23-24 1989. International Building Performance Simulation Association.

[Fani3] P.O. Faniger. Thermal Comfort. McGraw-Hill Book Compagny; New York. 1973.

[FBSI91] B. Flament, L. Blanc-Sommereux, and A. Neveu. A new technique for thermal modelling of buildings: The modal synthesis. In Procetdings of Building Simulation :91. Sophia-Antipolis. Nice. France. International Building Performance Simulation Association. 20-22 August 1991.

[FGG89] R. Faucomnier. A. Grelat, and P. Guillemard. Eléments d'analyse du régime dỵnamique en thermique du bâtiment. Technical report, Fédération Nationale du Bâtiment. St Remy Les Chevreuses, 1989.

[Fra92] Gaz De France. Allan. manuel de référence, allan. ${ }^{T M}$.2.4.1. Technical report, Gaz De France, June 1992.

[G.AC'91] G. Gan, H. B. Awbi. and D. J. Croome. Simulation of air flow in natu-

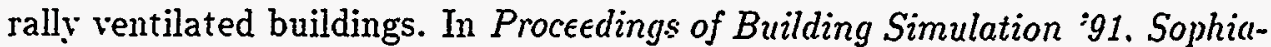
Antipolis. Nïce. France. International Building Performance Simulation Association, 20-22 August 1991.

[Gad80] Ashok Jagannath Gadgil. On convective heat transfer in building energy analysis. L.B.L. Report LBL-10900, Lawrence. Berkeley Laboratory, May 1980.

[HC91] J. L. M. Hensen and J. A. Clarke. A simulation approach to the evaluation of coupled heat and mass transfer in buildings. In Proceedings of Building Simulation 91. Sophia-Antipolis, Nice. France. International Building Performance Simulation Association, 20-22 August 1991.

[How85] A. T. Howarth. The prediction of air temperature variations in naturally ventilated rooms with convective heating. Building Service Engineering Research and Technology. 6(4):169-175, 1985. 
[HvdMR93] J. Hensen, J. van der Maas, and A. Roos. Air and heat flow through large vertical openings. In Proceedings of Building Simulation :9.3. Adelaide. Australia, pages 479-485. International Building Performance Simulation Association. 16-18 August 1993.

[Ina88] C. Inard. Contribution à l:̈́tude du couplage thermique entre un émetteur de chauffage $\epsilon$ t un local. PhD thesis, Institut National des Sciences Appliquées de Lyon, July 1988.

[K.J8:5] Milos Kionopasek and Sundaresan Jaravaman. Constraint and declarative languages for engineering applications: the th!solver contribution. Proceedings of the IEEE, $73(12)$, December 1985 .

[I.JH8T] A. K. Kulkarni, H. R. Jacobs, and J. J. Hwang. Similarity solution for natural convection flow over an isothermal vertical wall immersed in thermally stratified medium. International Journal of Heat and Mass Transfer. 30(t):691-698, 198T.

[LHF9:3] Y. Li, S. Holmberg; and L. Fuchs. Multi-grid prediction of conjugate heat transfer and air flow in buildings. In Proceedings of Building Simulation "9.3. Adelaide, Australia. International Building Performance Simulation Association, 16-18 August 1993.

[LIA.91] Ii. Limam. C. Inard. and F. Allard. Etude expérimentale des transferts de masse et de chaleur à travers les grandes ouvertures verticales. In létilation et renourellement d'air. Lyon, March 1991. GEVRA.

[L.Y8T] J. Lebrun and P. Aigendahumana. Air circulation induced by heating emitters and corresponding heat exchanges along the walls: test room results and modelling. In Procetdings of Room Vent 1987, Stockholm, 1987.

[LYT93] J. Lam. R. Yuen, and T. Tau. Improvements to user-friendliness of a computational fluid dỵamics ( $\mathrm{cfd}$ ) code for simulation of air movement in buildings. In Procetdings of Building Simulation 93. Adelaide, Australia. International Building Performance Simulation Association, 16-18 August 1993.

[MITS3] MIIT. MACSYMA Reference Manual. version 10. Cambridge, MA, 1983.

[AIP8:3] N. C. Markatos and C.A. Pericleous. Laminar and turbulent natural convection in an enclosed cavity. In Proceedings of The 21st National Heat Transfer Conference, Seattle, Washington. July 24-28 1983.

[MP84] I. C. Markatos and C. A. Pericleous. Laminar and turbulent natural convection in an enclosed cavity. International Journal of Heat and mass Transfer. $2 i(5): 75.5-772,1984$.

[Nat92] Jean-Michel Nataf. Algorithm of simplification of nonlinear equations systems. ACM SIGSAM Bulletin, 26(1), July $1992^{\circ}$.

[NivdTi93] J. Niu and J. van der Kiooi. Dynamic simulation of combination of evaporative cooling with cooled ceiling system for office room cooling. In Proceedings of Building Simulation "93. Adelaide, Australia. International Building Performance Simulation Association, 16-18 August 1993.

[NIV93] Jean-Michel Nataf and Etienne Wurtz. Application of the spark environment to $3 \mathrm{~d}$ air flow problems. In Proceedings of Building Simulation :93. Adelaide. A ustralia. International Building Performance Simulation Association, August 1993. 
[NW94] Jean-Michel Nataf and Frederick Winkelmann. Symbolic modeling in building energy simulation. LBL Report LBL-35439. Lawrence Berkeley Laboratory. April 1994.

[Oku87] Hirovasu Okuyama. Theoretical Study on the Building Thermal Network Model (in Japanese). PhD thesis. Waseda Lniversity, December 1987.

[R.AC93] E. A. Rodriguez, S. Alvarez, and I. Caceres. Prediction of indoor temperature and air flow patterns by means of simplified zonal models. In Proceedings of ISES Solar World Congress. 1993. Budapest. Hungary, volume 6, 1993.

[RAC94] Eduardo A. Rodriguez, Servando Alvarez, and Juan F. Coronel. Modelling stratification patterns in detaild building simulation codes. In Procetdings of European Conference on Energy Performance and Indoor Climate in Buildings, 1994. Lyon, France, 24-26 November 1994.

[Sah88] Per Sahlin. IDA, a Modelling and Simulation Environment for Building Applications. Institute of Applied Mathematics. P.O. Box 26300, S-100 41 Stockholm, Sweden. Stockolm, Sweden. 1988.

[SBX89] Edward F. Sowell, Walter F. Buhl. and Jean-MIichel Nataf. Object-oriented programming. equation-based submodels. and system reduction in spank. In


Columbia. Canada, June 1989. International Building Performance Simulation Association. P.O. 282. Orleans. Ontario. K1C. 1ST, Canada.

[SGT81] G. Shiralkar, A. Gadgil, and C. L. Tien. High rayleigh number convection in shallow enclosures with different end temperatures. International Journal of Heat and mass Transfer, 24(10):1621-1629, 1981.

[S.I91] Ara Setrakian and Don McLean. Building simulations using thermal and cfd models. In Procetdings of Building Simulation 91, Sophia-Antipolis, Nice. France. International Building Performance Simulation Association. 20-22 August 1991.

[SNW90] Edward F. Sowell. Jean-Michel Nataf. and Frederick C. Winkelmann. Radiant transfer due to lighting: An example of symbolic model generation for the simulation problem analysis kernel. LBL Report LBL-28273, Lawrence Berkeley Laboratory: January 1990.

[Sol88] Solar Energy Laboratory, University of Wisconsin-Madison. TRNSYS. a Transient Simulation Program. 1988.

[SS93] S. Stankovic and A. Setrakian. Thermal and cfd modelling vs. wind tunnel in

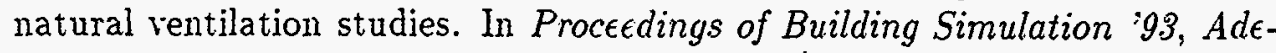
laide. Australia. International Building Performance Simulation Association, 16-18 August 1993.

[SYi1] E. M. Sparrow and H. S. Yu. Local non-similarity thermal boundary-layer solutions. Journal of Heat Transfer. pages 328-334, November 1971.

[TG82] J. Tichy and A. Gadgil. High rayleigh number laminar convection in low aspect ratio enclosures with adiabatic horizontal walls and differentially heated vertical walls. Journal of Heat Transfer. 104:103-110, February 1982. 
[TS93] T. Tsuchiva and K. Sakano. Computer simulation of multiroom temperature and humidity variation under variable infiltration conditions. In Procetdings of Building Simulation 9.3. Adelaide. A ustralia. International Building Performance Simulation Association. 16-18 August 1993.

[Iial84] George N. Walton. A computer algorithm for predicting infiltration and interrom airflows. ASHRAE Transactions. 90, 1984.

[Wur9.5] Etienne Wurtz. Modelisation tridimensionnelle des transferts thermiques et aérauliques dans le batiment en environnement orienté objet. $\mathrm{PhD}$ thesis. École Nationale des Ponts et Chaussées, December 201995. 